\title{
WETTABILITY AND PREDICTION OF OIL RECOVERY FROM RESERVOIRS DEVELOPED WITH MODERN DRILLING AND COMPLETION FLUIDS
}

\author{
Semiannual Report
}

1 April 2002 through September 30, 2002

Principal Investigator:

Jill S. Buckley

Co-Investigator:

Norman R. Morrow
PRRC, New Mexico Institute of Mining and Technology

Dept. of Chemical \& Petroleum Eng., University of Wyoming

December 2002

DE-FC26-01BC15164

\author{
Submitted by: \\ New Mexico Petroleum Recovery Research Center \\ New Mexico Institute of Mining and Technology \\ 801 Leroy Place \\ Socorro NM 87801 \\ Department of Chemical and Petroleum Engineering \\ University of Wyoming \\ P.O. Box 3295 \\ Laramie, WY 82071-3295 \\ PRRC 02-24
}




\section{Disclaimer}

This report was prepared as an account of work sponsored by an agency of the United States Government. Neither the United States Government nor any agency thereof, nor any of their employees, makes any warranty, express or implied, or assumes any legal liability or responsibility for the accuracy, completeness, or usefulness of any information, apparatus, product, or process disclosed, or represents that its use would not infringe privately owned rights. Reference herein to any specific commercial product, process, or service by trade name, trademark, manufacturer, or otherwise does not necessarily constitute or imply its endorsement, recommendation, or favoring by the United States Government or any agency thereof. The views and opinions of authors expressed herein do not necessarily state or reflect those of the United States Government or any agency thereof. 


\title{
Project Objectives
}

The objectives of this project are:

(1) to improve understanding of the wettability alteration of mixed-wet rocks that results from contact with the components of synthetic oil-based drilling and completion fluids formulated to meet the needs of arctic drilling;

(2) to investigate cleaning methods to reverse the wettability alteration of mixed-wet cores caused by contact with these SBM components; and

(3) to develop new approaches to restoration of wetting that will permit the use of cores drilled with SBM formulations for valid studies of reservoir properties.

\begin{abstract}
We report on a preliminary study of wetting effects of synthetic oil-based mud components on the wetting of mica surfaces using drilling mud fractions obtained from two wells drilled with synthetic oil-based muds (SBM). We have used these SBM fractions, one a filtrate and the other a centrifugate, to develop testing protocols for studies on smooth mica surfaces.

Both SBM fractions changed the wetting of clean, dry mica surfaces, making them preferentially oil-wet. Solvents were tested to clean the mica with varying degrees of success. In tests designed to simulate contact between SBM fractions and reservoir pore surface, changes of wetting of mica that had previously been exposed to brine and crude oil were examined using six different crude oils in combination with several different brine formulations. Four of the six oils produced preferentially water-wet surfaces whereas two produced fairly oil-wet conditions on mica. Exposure to the SBM fractions tended to increase decane/water advancing contact angles on the more water-wet surfaces and to decrease those on the more oil-wet surfaces. Cleaning solvents were compared for their efficacy and the possibility of wettability restoration was examined for some of the cleaned surfaces.
\end{abstract}




\section{Table of Contents}

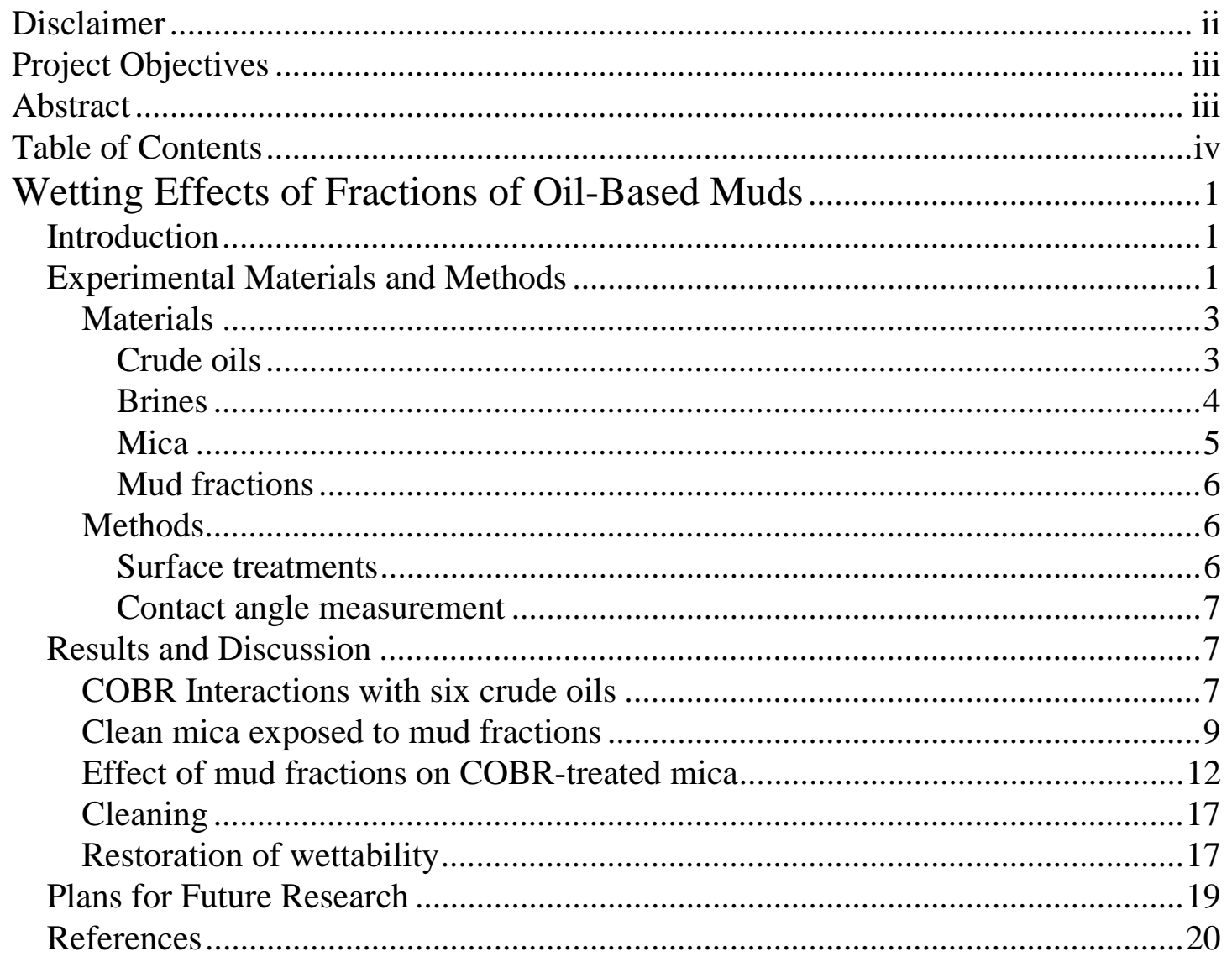




\title{
Wetting Effects of Fractions of Oil-Based Muds
}

\author{
Ratna Kumar Lekkala and Jill S. Buckley
}

\section{Introduction}

In a preliminary study of wetting effects of synthetic oil-based mud components on the wetting of mica surfaces, drilling mud fractions obtained from two wells drilled with synthetic oil-based muds (SBM) were used to evaluate their effects on wettability. These materials, one a filtrate and the other a centrifugate, have helped with development of testing protocols for studies of wettability alteration due to exposure to synthetic oilbased muds on smooth mica surfaces. It is difficult to generalize from the results of these tests because neither the composition nor the method of preparation of the mud fraction samples was well documented. Nevertheless, this work will provide some guidance when more carefully controlled mixtures and conditions are used as to whether the controlled conditions accurately reflect the phenomena observed under more realistic conditions.

In the absence of either brine or crude oil, components from the drilling mud can adsorb directly on the mica surface. The extent of persistent adsorption was tested by rinsing off the filtrate or centrifugate with toluene, immersing the surface in decane, and measuring contact angles between decane and a drop of water.

In an oil reservoir, drilling mud filtrate replaces the brine and crude oil that originally filled the pore space and equilibrated with the surface. The previously established wetting condition dictates the distribution of water and oil on the microscopic scale. To test the effects of filtrate and centrifugate on surfaces that have already been exposed to brine and crude oil, six crude oils were selected for testing with several different brine compositions. Four of the oils produced weakly water-wet surfaces with a variety of brines. Two oils altered wetting to more oil-wet conditions.

The extent of cleaning by a variety of organic solvents and solvent sequences was tested for the mica exposed directly to mud filtrate and centrifugate. Samples exposed first to brine and crude oil, then aged in one of the mud fractions were also cleaned. Effectiveness of cleaning was assessed by re-measuring decane/water contact angles. Finally, some of the cleaned samples were exposed again to brine and oil to judge the extent to which restoration of the original wetting conditions might be feasible.

\section{A Brief Review of COBR Interactions and Wettability Tests on Smooth Surfaces}

Crude oil/brine/rock (COBR) interactions have been the subject of considerable previous study that forms the basis for the design of tests of the effects of .the SBM fractions. Those previous studies have shown that the composition of the brine phase that initially occupies the pore space is as important as the compositions of the crude oil and 
mineral surfaces in determining the course of the interactions that contribute to alteration of wetting (Buckley et al., 1989). A brief introduction will help to provide context for the study that follows.

Several mechanisms of interactions between crude oils, brines and mineral surfaces have been identified (Buckley et al., 1998). These include ionic interactions that occur between oil components and mineral surfaces that are influenced by brine strength and composition and surface precipitation that can dominate when asphaltenes are close to the onset of flocculation. (Al-Maamari and Buckley, 2000). Ionic interactions can be further subdivided into simple acid-base interactions that can be tested using brines with monovalent ions (including the $\mathrm{pH} 4$ and $\mathrm{pH} 8$ buffers used in this study) and more the more complex interactions that can occur when brines contain ions of higher valency, represented in this study by the three reservoir brines. When acid/base interactions dominate, no wetting change is observed if there is a stable water film between oil and solid. This situation occurs when there is sufficient electrostatic repulsion between a negatively charged oil/water interface and the negatively charged mica surface. For many basic oils a stable water film of the $\mathrm{pH} 8$ buffer prevents wetting alteration. An unstable water film often results from the use of the $\mathrm{pH} 4$ buffer because the basic oil interface is positively charged and the mica is negatively charged. In this situation oil components can adsorb, altering the wetting of the mica surface, which is indicated by high wateradvancing angles between water and decane. The $\mathrm{pH} 4$ and $\mathrm{pH} 8$ brines used in our standard tests have been selected in an attempt to produce wetting changes that bracket the minimum and maximum amount of wetting alteration caused by any given crude oil.

The nature of the surface also plays a role in these interactions. Mica is a convenient model silicate surface because it is widely studied and thus well characterized (Liu and Buckley, 1999). A freshly cleaved mica surface is molecularly smooth with a negative surface charge in all brines except those with $\mathrm{pH}$ less than 2. Quartz surfaces are also negatively charged at these conditions, but the surface charge density could well be different than that of mica. Thus the results of these tests provide qualitative indications of the wetting of quartz and other silicate surfaces.

Contact angles - by convention the angle through the water phase at the line of contact between water, oil, and solid-are a measure of that solid's wettability when the two fluids and the solid are all pure substances. The situation with brines and crude oils is considerably more complicated. Most minerals, including quartz and mica, are strongly water-wet; a drop of water spreads over an oil-covered surface if the oil is a pure hydrocarbon or clean mineral oil. Crude oils contain components that can adsorb on the mineral surface, thus changing its effective wetting (see Buckley, 2001, for a review of work in this area). Measurements of contact angles using a drop of crude oil trapped against a mineral surface that is immersed in brine show contact angles that are low and unchanging with time, but the surface under the oil drop is changing. When the drop is moved so that water advances over the oil-covered portion of the surface, the wateradvancing contact angle can be much larger (less water-wet or oil-wet). The angle is a function not only of oil, brine, and surface compositions, but also of exposure time and 
temperature. Often the angle cannot be measured because the three-phase contact line is pinned or because rigid films develop at the oil/water interface.

To circumvent the problems that arise in measuring contact angles directly with crude oils, a protocol has been developed in which clean surfaces are equilibrated first with an aqueous solution, then with oil. Time and temperature of exposure to oil can be varied. Contact angles can be widely varying on a surface that has been aged for only a few days in oil. Three weeks has been found by experience to produce more stable results. After exposure, bulk crude oil is removed by gently rinsing with a solvent such as toluene that does not precipitate asphaltenes. The surface can then be transferred to decane, a poor asphaltene solvent, without drying, or it can be dried and immersed in water or another aqueous solution. A drop of the second phase (water or decane) is formed on the surface and contact angles can be measured between these probe fluids on the oil-treated surface. If, for example, the rinsed sample is immersed in decane, a captive drop of water can be expanded across the surface to measure the water-advancing angle $\left(\theta_{\mathrm{A}}\right)$. If the water drop size is decreased, the water-receding angle can be measured. Usually these angles are measured quasi-statically a few minutes after the drop has been advanced or receded. For a surface in water, the enlargement of a drop of decane produces a water-receding condition and vice versa. The terms advancing and receding refer to the reference phase, in this case water, not necessarily to the drop.

\section{Experimental Materials and Methods}

\section{Materials}

\section{$\underline{\text { Crude oils }}$}

Selected chemical and physical properties of six stock-tank crude oils used in this study are summarized in Table 1 . The oils were used as received. 
Table 1. Properties of crude oils.

\begin{tabular}{|c|c|c|c|c|c|c|}
\hline Oil & C-A2-00 & C-B2-01 & C-K-01 & C-L-01 & E-1XC0-01 & S-Ven-41 \\
\hline API Gravity ( $\left.{ }^{\circ} \mathrm{API}\right)$ & 22.7 & 37.1 & 18.9 & 34.0 & 33.8 & 28.7 \\
\hline Average MW (Daltons) & 306 & 196 & 319 & 216 & 218 & 243 \\
\hline $\mathrm{RI}$ at $20^{\circ} \mathrm{C}$ & 1.5146 & 1.4739 & 1.5287 & 1.4779 & 1.4795 & 1.4985 \\
\hline $\mathrm{n}-\mathrm{C}_{7} \mathrm{P}_{\mathrm{RI}}\left(20^{\circ} \mathrm{C}\right)$ & 1.4368 & 1.4263 & 1.4324 & 1.4261 & 1.4163 & 1.4504 \\
\hline $\mathrm{n}-\mathrm{C}_{7}$ Asphaltene $(\%)$ & 4.34 & 1.33 & 3.52 & 1.39 & 0.65 & 7.17 \\
\hline Density at $20^{0} \mathrm{C}\left(\mathrm{g} / \mathrm{cm}^{3}\right)$ & 0.9105 & 0.8361 & 0.9374 & 0.8515 & 0.8531 & 0.8812 \\
\hline Acid \#, $\mathrm{N}_{\mathrm{A}}(\mathrm{mg} \mathrm{KOH} / \mathrm{g}$ oil $)$ & 1.28 & 0.50 & 0.99 & 0.35 & 0.18 & 0.43 \\
\hline Base \#, $\mathrm{N}_{\mathrm{B}}(\mathrm{mg} \mathrm{KOH} / \mathrm{g}$ oil $)$ & 5.64 & 2.67 & 5.21 & 2.29 & 1.93 & 1.78 \\
\hline $\mathrm{N}_{\mathrm{B}} / \mathrm{N}_{\mathrm{A}}$ & 4.41 & 5.34 & 5.29 & 6.63 & 10.7 & 4.14 \\
\hline Saturates & 58.1 & 68.5 & 52.8 & 66.3 & 78.5 & 60.0 \\
\hline Aromatics & 11.9 & 17.5 & 19.0 & 16.7 & 18.1 & 18.3 \\
\hline Resins & 23.4 & 12.7 & 24.8 & 13.2 & 9.7 & 14.5 \\
\hline Viscosity (cp) & 127.8 & 6.4 & 396 & 19.1 & 9.3 & 33.7 \\
\hline
\end{tabular}

\section{$\underline{\text { Brines }}$}

Reservoir brine $(\mathrm{RB})$ compositions for the reservoirs corresponding to the $\mathrm{C}-\mathrm{K}$ 01, C-L-01, and C-B2-01 oils were available, as shown in Table 2; these oils were tested with their respective synthetic reservoir brines. No comparable information was available for the other three crude oils. Synthetic sea water (SSW) was made up according to the specifications in Table 3. Compositions of brines with controlled $\mathrm{pH}$ and $\mathrm{NaCl}$ concentrations, formulated to maximize $(\mathrm{pH} 4)$ or minimize $(\mathrm{pH} 8)$ the stability of thin water films between mica and oil are listed in Table 4. 
Table 2. Synthetic reservoir brines.

\begin{tabular}{|c|c|c|c|c|}
\hline & Units & RB $(\mathbf{C}-\mathbf{K}-\mathbf{0 1})$ & RB $(\mathbf{C}-\mathbf{L}-\mathbf{0 1})$ & RB $(\mathbf{C}-\mathbf{B 2 - 0 1})$ \\
\hline Chloride & $\mathrm{mg} / \mathrm{l}$ & 19900 & 44800 & 31900 \\
\hline Sulphate & $\mathrm{mg} / \mathrm{l}$ & 17 & 5 & 170 \\
\hline Bicarbonate & $\mathrm{mg} / \mathrm{l}$ & 950 & 640 & 500 \\
\hline Acetate & $\mathrm{mg} / \mathrm{l}$ & 1400 & 0 & 1780 \\
\hline Sodium & $\mathrm{mg} / \mathrm{l}$ & 11800 & 25900 & 21000 \\
\hline Potassium & $\mathrm{mg} / \mathrm{l}$ & 150 & 140 & 136 \\
\hline Magnesium & $\mathrm{mg} / \mathrm{l}$ & 120 & 320 & 117 \\
\hline Calcium & $\mathrm{mg} / \mathrm{l}$ & 420 & 1200 & 1180 \\
\hline TDS & $\mathrm{mg} / 1$ & 34000 & 75100 & 58000 \\
\hline $\mathrm{pH}$ at $25^{\circ} \mathrm{C}$ & & 7.47 & 5.93 & 7.26 \\
\hline Density at $25^{\circ} \mathrm{C}$ & $\mathrm{g} / \mathrm{ml}$ & 1.023 & 1.05 & 1.035 \\
\hline
\end{tabular}

Table 3. Synthetic sea water (SSW)

\begin{tabular}{|l|l|l|l|l|l|}
\hline Brine & $\begin{array}{c}\text { NaCl } \\
(\mathbf{g} / \mathbf{L})\end{array}$ & $\begin{array}{l}\mathrm{CaCl}_{2}\left(\mathbf{2 H}_{2} \mathbf{O}\right) \\
(\mathbf{g} / \mathbf{L})\end{array}$ & $\begin{array}{l}\mathrm{MgCl}_{2}\left(\mathbf{6 H}_{2} \mathbf{O}\right) \\
(\mathbf{g} / \mathbf{L})\end{array}$ & $\begin{array}{l}\mathbf{N a H C O} \\
(\mathbf{g} / \mathbf{L})\end{array}$ & $\begin{array}{l}\mathrm{Na}_{2} \mathrm{SO}_{4} \\
(\mathbf{g} / \mathrm{L})\end{array}$ \\
\hline $\mathrm{SSW}$ & 24.0031 & 1.4673 & 10.6400 & 0.03864 & 3.1959 \\
\hline
\end{tabular}

Table 4. Buffers

\begin{tabular}{|c|c|c|c|c|c|}
\hline Brine & $\begin{array}{c}\mathbf{C H}_{3} \mathbf{C O O N a} \\
(\mathbf{g} / \mathbf{L})\end{array}$ & $\begin{array}{c}\mathbf{C H}_{3} \mathbf{C O O H} \\
(\mathbf{m l} / \mathbf{L})\end{array}$ & $\begin{array}{c}\mathbf{N a C l} \\
(\mathbf{g} / \mathbf{L})\end{array}$ & $\begin{array}{c}\mathbf{N a}_{2} \mathbf{H P O}_{4} \\
(\mathbf{g} / \mathbf{L})\end{array}$ & $\begin{array}{c}\mathbf{N a}_{2} \mathbf{H P O}_{4} \\
(\mathbf{g} / \mathbf{L})\end{array}$ \\
\hline $\mathrm{pH} 4,0.01 \mathrm{M} \mathrm{NaCl}$ & 0.73827 & 2.342863 & & & \\
\hline $\mathrm{pH} 8,1 \mathrm{M} \mathrm{NaCl}$ & & & 47.0442 & 13.44361 & 0.635894 \\
\hline
\end{tabular}

\section{$\underline{\text { Mica }}$}

Sheets of Muscovite mica were obtained from S \& J Trading Inc. Large stacks of mica were separated into samples a few layers thick. Sheets were cut into samples of about $1 \mathrm{~cm}$ by $2 \mathrm{~cm}$. Final cleaning was accomplished by pressing adhesive tape to top and bottom layers and pulling apart slowly to expose two fresh surfaces.

Contact angles measured for water advancing against decane on clean mica surfaces that were aged for 24 hours in selected brines were all less than $5^{\circ}$, as shown in Table 5. 
Table 5. Water-advancing angles on clean mica.

\begin{tabular}{|c|c|c|c|}
\hline & \multicolumn{3}{|c|}{ Water/decane advancing contact angles $\left(^{\circ}\right)$} \\
on mica substrates aged in:
\end{tabular}

\section{$\underline{\text { Mud fractions }}$}

Two samples, obtained from synthetic oil-base drilling muds (SBMs) used in the wells that produced Oils C-K-01 and C-L-01, were used in this study. One was a filtered "end of run" sample. The other was the supernatant from a centrifuged sample. They will be referred to as K-f for the filtrate and L-c for the centrifugate, respectively. Note that they are from different sources, not simply from different separation processes.

A disadvantage of using these field samples is that little information was available about the components of the two drilling fluids, nor were there details available regarding how the filtrate and centrifugate were prepared. Nevertheless, the opportunity to test samples of real synthetic drilling fluid fractions outweighed the scientific uncertainties, some of which will be addressed in later phases of this project. Addition measurements with fluids and cores from the reservoirs represented by these mud fractions were presented recently (McCaffery et al., 2002).

\section{Methods}

\section{$\underline{\text { Surface treatments }}$}

Clean mica surfaces were treated using the protocol developed in previous work on wettability alteration by crude oils (e.g., Liu and Buckley, 1997, 1999), with the addition of steps in which the samples were exposed to the mud fractions and to various cleaning agents. Unless otherwise specified, mica was first equilibrated with brine for a period of one day, then the samples were drained, but not dried, and exposed to crude oil for at least 3 weeks. Room temperature is the standard condition for both brine and oil aging steps. To examine the surface, bulk crude oil was removed by rinsing the sample with a small amount of toluene. Toluene is a good asphaltene solvent and thus does not cause asphaltene precipitation from the bulk oil. Following the removal of bulk oil, the samples were submerged in decane, a poor asphaltene solvent that minimizes further changes in the material deposited on the mica surface. Samples treated by this sequence of brine and oil are termed COBR samples since they mimic the sequence of crude 
oil/brine/rock interactions that occur in an oil reservoir. Decane and water were used as probe fluids to examine the extent of wetting alteration. An outline of this study is given in Fig. 1.

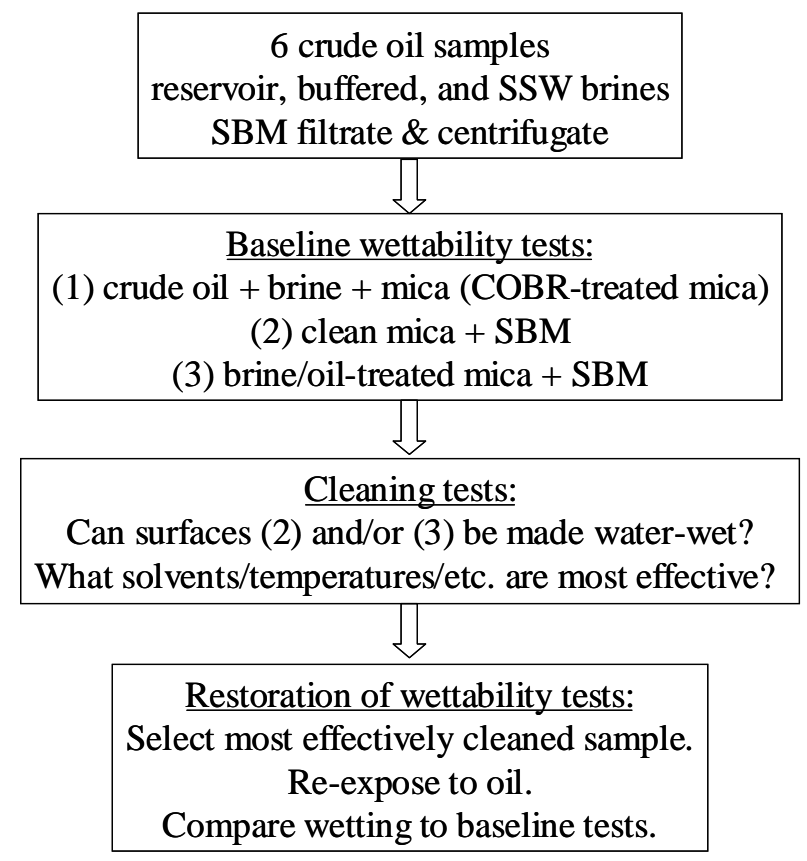

Figure 1. Outline of the test plan.

\section{Contact angle measurement}

The protocol developed during previous projects to assess the extent of wetting alteration on surfaces after they have been contacted with brine and crude oil has been adopted for this project. Treated surfaces from which bulk oil has been removed by rinsing with toluene (a good asphaltene solvent that does not precipitate asphaltenes during the rinsing step) were submerged in decane (a poor asphaltene solvent in which material adsorbed on the mica surface is stable). A drop of water was formed with a microburet and first advanced, then receded over the decane-covered surface. After advancing or receding by enlarging or reducing the water drop volume, the interface was allowed to equilibrate for at least two minutes before the contact angle was recorded. At least six different locations were tested on each treated mica surface. Average contact angle values and standard deviations are reported.

\section{Results and Discussion}

\section{COBR Interactions with six crude oils}

Interactions between the selected crude oils and wet mica samples were examined in order to establish a baseline against which the effects of mud contamination could be 
judged (Table 6). Figure 2 summarizes advancing (Fig. 2a) and receding (Fig. 2b) contact angles between decane and water for four of the six oils. Contact angles depended, to some extent, on the composition of the pre-equilibrating brine, but in none of these cases did the water-advancing angles exceed $60^{\circ}$. This group of oils is therefore designated as the water-wet or WW group. Results of similar tests for the remaining two oils are shown in Fig. 3. More oil-wet conditions were produced by these two oils, forming the OW group.

Table 6. Contact angles of mica aged in brines (1 day) and oils ( 21 days)

\begin{tabular}{|c|c|c|c|c|c|c|c|}
\hline & & & & & & \\
\hline & & C-A2-00 & C-B2-01 & C-K-01 & C-L-01 & E-1XC0-01 & S-Ven-41 \\
\hline Brine & & \multicolumn{6}{|c|}{ Decane - Water Contact Angles $\left({ }^{\circ}\right)$} \\
\hline \multirow{2}{*}{$\underset{I=0.01 M}{\text { pH 4, }}$} & $\boldsymbol{\theta}_{\mathrm{A}}$ & $51 \pm 4$ & $44 \pm 3$ & $30 \pm 5$ & $54 \pm 4$ & $136 \pm 5$ & $128 \pm 5$ \\
\hline & $\theta_{\mathrm{R}}$ & $23 \pm 4$ & $8 \pm 3$ & $16 \pm 1$ & $24 \pm 3$ & $61 \pm 3$ & $55 \pm 3$ \\
\hline \multirow{2}{*}{ pH 8, I=1.0M } & $\theta_{\mathrm{A}}$ & & $43 \pm 3$ & $32 \pm 5$ & $35 \pm 5$ & & \\
\hline & $\theta_{\mathrm{R}}$ & & $12 \pm 1$ & $14 \pm 2$ & $15 \pm 2$ & & \\
\hline \multirow{2}{*}{$\mathbf{R B}$} & $\theta_{\mathrm{A}}$ & & $54 \pm 5$ & $48 \pm 3$ & $24 \pm 3$ & & \\
\hline & $\theta_{\mathrm{R}}$ & & $9 \pm 2$ & $16 \pm 2$ & $9 \pm 1$ & & \\
\hline \multirow{2}{*}{ SSW } & $\theta_{\mathrm{A}}$ & $49 \pm 3$ & & & & $143 \pm 6$ & $133 \pm 5$ \\
\hline & $\theta_{\mathrm{R}}$ & $19 \pm 2$ & & & & $55 \pm 6$ & $61 \pm 3$ \\
\hline
\end{tabular}

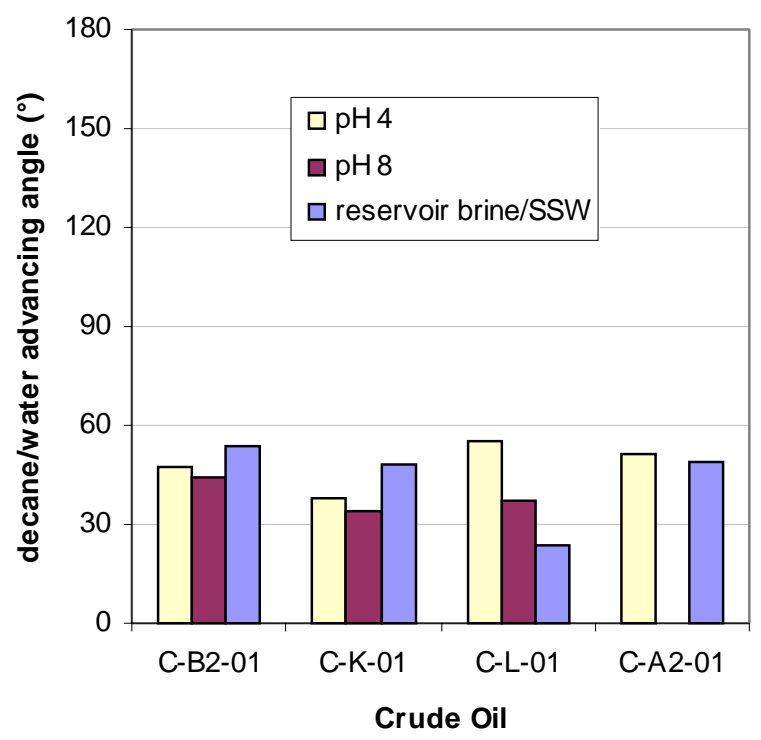

(a) water-advancing angles

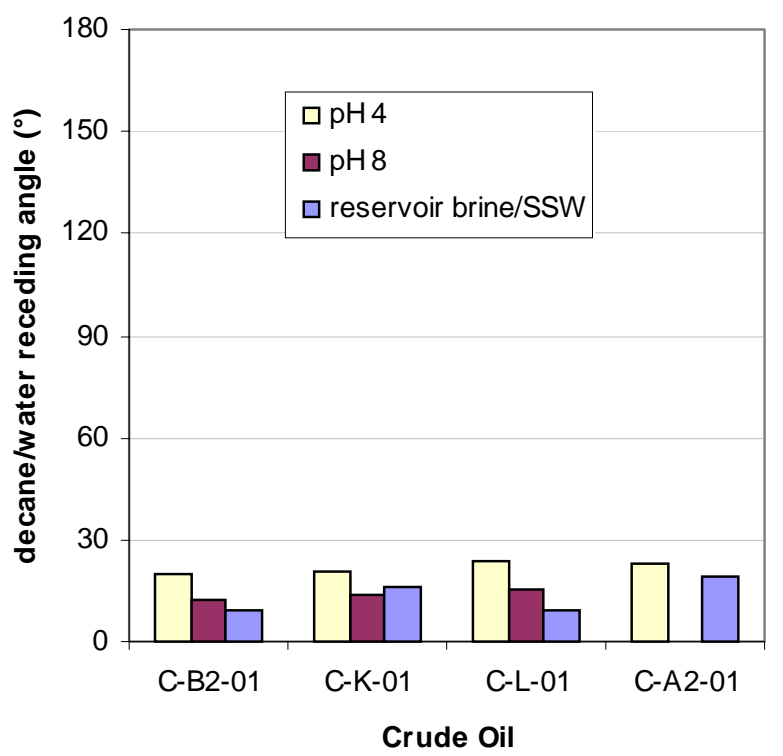

(b) water-receding angles

Figure 2. Results of standard COBR treatments with the WW oils. 


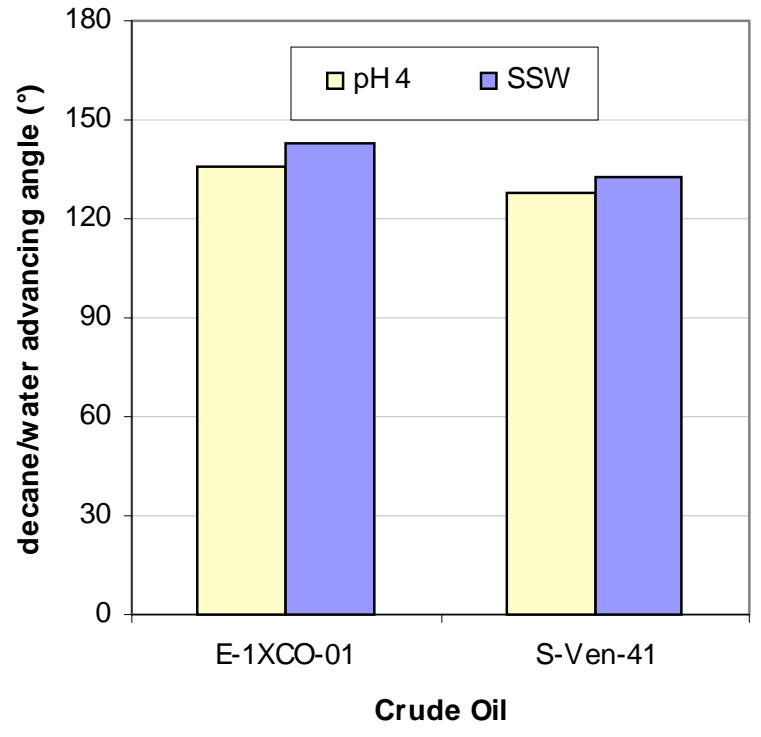

(a) water-advancing angles

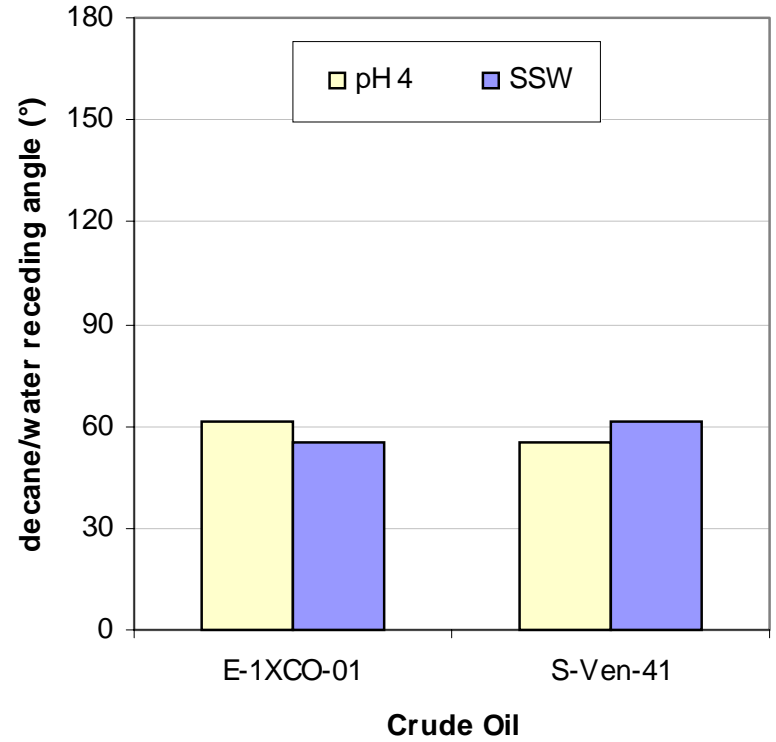

(b) water-receding angles

Figure 3. Results of standard COBR treatments with the OW oils

\section{Clean mica exposed to mud fractions}

Mica exposed to a pure hydrocarbon, even for an extended period of time, would remain water-wet. That is not what happens when mica was aged in either K-f or L-c fractions of synthetic oil-based drilling fluids, as summarized in Table 7 and shown in Fig. 4. The legend indicates the mud fraction used in these treatments and, in parentheses, the probe oil used to measure the water advancing angles reported. Use of crude oil as the probe oil necessitated drying of the rinsed surfaces prior to submerging in water. A drop of crude oil was formed against the mica surface under water. These angles tended to be somewhat larger (more oil-wet) than those measured with decane as the probe oil. One week of aging appeared to be sufficient to produce the maximum wettability alteration effect with both K-f and L-c fractions. 
Table 7. Contact angles for dry mica samples aged in mud fractions.

\begin{tabular}{|c|c|c|c|}
\hline & & K-f filtrate & L-c centrifugate \\
\hline Aging time & \multicolumn{3}{|c|}{$\begin{array}{l}\text { Decane - Water Contact Angles }\left(^{\circ}\right) \\
\text { oil drop in water or water drop in oil }\end{array}$} \\
\hline \multirow{2}{*}{1 day } & $\theta_{\mathrm{A}}$ & $65 \pm 4$ & $108 \pm 4$ \\
\hline & $\theta_{\mathrm{R}}$ & $15 \pm 2$ & $24 \pm 2$ \\
\hline \multirow{2}{*}{7 days } & $\theta_{\mathrm{A}}$ & $121 \pm 8$ & $131 \pm 2$ \\
\hline & $\theta_{\mathrm{R}}$ & $32 \pm 2$ & $30 \pm 2$ \\
\hline \multirow{3}{*}{21 days } & $\theta_{\mathrm{A}}$ & $117 \pm 6$ & $106 \pm 4$ \\
\hline & $\theta_{\mathrm{R}}$ & $29 \pm 2$ & $27 \pm 3$ \\
\hline & \multicolumn{3}{|c|}{$\begin{array}{l}\text { Crude Oil - Water Contact Angles }\left(^{\circ}\right) \\
\text { oil drop in water } \\
\end{array}$} \\
\hline \multirow{2}{*}{1 day } & $\theta_{\mathrm{A}}$ & & $136 \pm 2$ \\
\hline & $\theta_{\mathrm{R}}$ & & $31 \pm 2$ \\
\hline \multirow{2}{*}{7 days } & $\theta_{\mathrm{A}}$ & $126 \pm 5$ & $135 \pm 10$ \\
\hline & $\theta_{\mathrm{R}}$ & $36 \pm 3$ & $30 \pm 2$ \\
\hline \multirow{2}{*}{21 days } & $\theta_{\mathrm{A}}$ & $139 \pm 9$ & $155 \pm 6$ \\
\hline & $\theta_{\mathrm{R}}$ & $31 \pm 3$ & $33 \pm 2$ \\
\hline
\end{tabular}

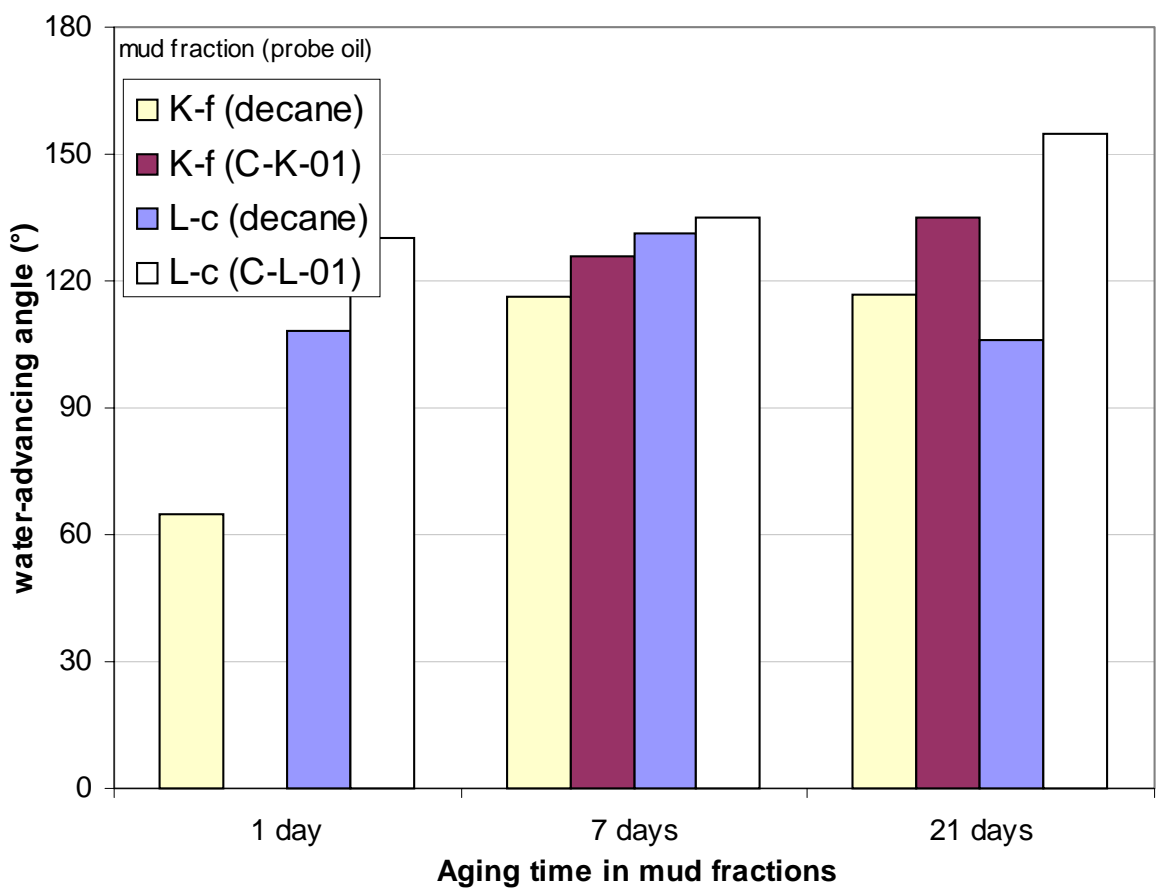

Figure 4. Water advancing contact angles on mica surfaces exposed to synthetic oil-based mud fractions for 1 day, 7 days, and 21 days. 
The high advancing angles measured after exposure of clean, dry mica to the two mud fractions confirm that they contain surface active materials, despite the fact that they have both been used in the field where surfactants would have adsorbed on cuttings and other solid surfaces and in spite of further removal of surfactants during filtration of the K-f sample or removal of adsorbed material with the solids separated in the centrifugation of the L-c sample. The results in Fig. 4 also show that rinsing with toluene does not remove the adsorbed material.

Some of the surface-active material can be removed by further washing, as summarized in Table 8 and shown in Fig. 5. Methanol was the most effective solvent of the three organic compounds investigated and cleaning of the mica treated with K-f was more efficient than cleaning of the L-c-treated mica. These results are consistent with the likely removal of the most active surfactant materials remaining in the end-of-run mud during the filtration process. In the centrifugate, surfactants in excess of those adsorbed on the solids existing in the mud, could remain in the supernatant. Thus stronger interactions might be expected with the L-c mud fraction than with K-f. There may also, however, be differences in original formulation and in the changes that occurred during drilling that contribute to differences between these two mud fractions.

Table 8. Contact angles on initially dry mica aged in mud fractions and washed with different solvents.

\begin{tabular}{|l|l|l|l|l|}
\hline Solvents used for washing & \multicolumn{2}{|l|}{ Mica aged in K-f filtrate } & \multicolumn{2}{l|}{ Mica aged in L-c centrifugate } \\
\hline & $\boldsymbol{\theta}_{\mathbf{A}}(\mathbf{d e g})$ & $\boldsymbol{\theta}_{\mathbf{R}}(\mathbf{d e g})$ & $\boldsymbol{\theta}_{\mathbf{A}}(\mathbf{d e g})$ & $\boldsymbol{\theta}_{\mathbf{R}}(\mathbf{d e g})$ \\
\hline Methylene chloride & $40 \pm 2$ & $12 \pm 1$ & $99 \pm 14$ & $34 \pm 6$ \\
\hline 1- Propanol & $29 \pm 2$ & $10 \pm 2$ & $64 \pm 2$ & $25 \pm 1$ \\
\hline Methanol & $30 \pm 1$ & $12 \pm 1$ & $50 \pm 1$ & $9 \pm 1$ \\
\hline
\end{tabular}




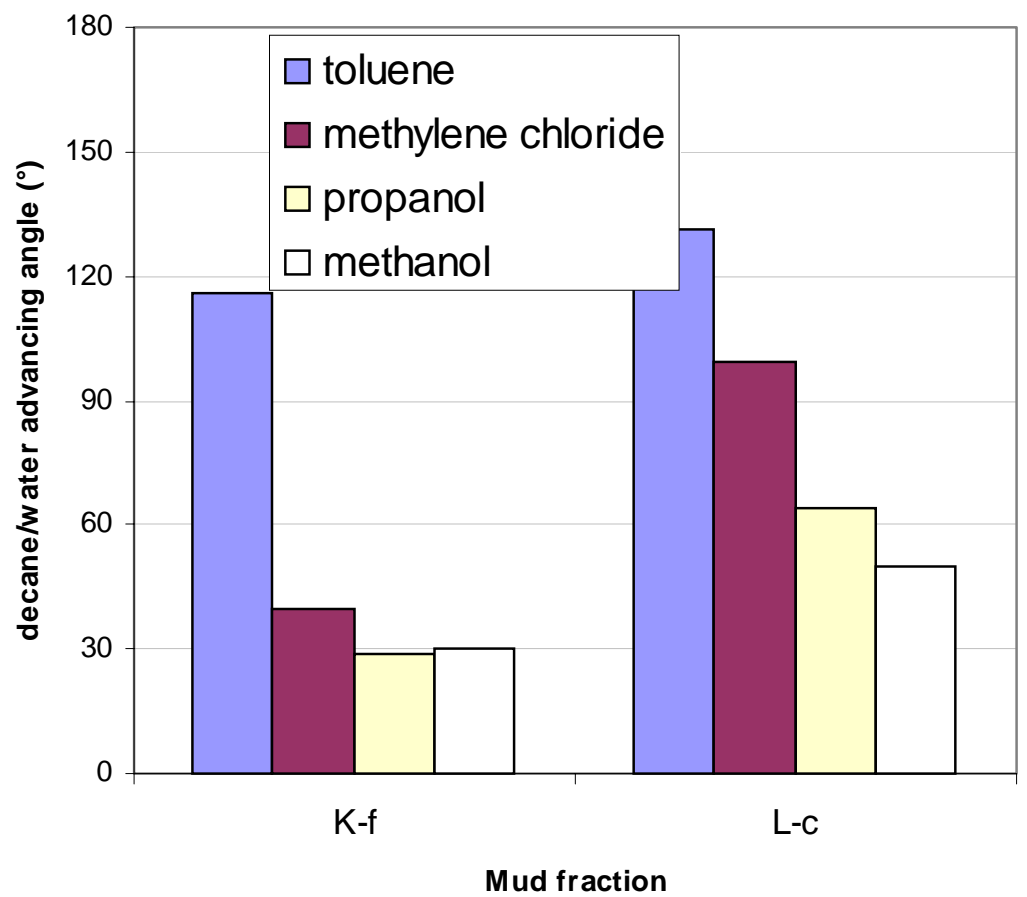

Figure 5. Dry mica samples treated with drilling mud fractions were cleaned by washing with organic solvents.

\section{Effect of mud fractions on COBR-treated mica}

Rather than mud components contacting clean, dry mica, a somewhat more realistic scenario would be to have mud components contact surfaces that have already been exposed to connate brine. The ability of the mud fractions to alter wetting on wet mica surfaces is shown by the data summarized in Table 9 .

Table 9. Contact angles of mica aged brine for one day and in mud fractions for seven days.

\begin{tabular}{|c|c|c|c|}
\hline Reservoir brine & Mud sample & Advancing angle $\left(^{\circ}\right)$ & Receding angle $\left(^{\circ}\right)$ \\
\hline RB (C-L-01) & L-c & $135 \pm 6$ & $53 \pm 4$ \\
\hline RB (C-B2-01) & K-f & $105 \pm 5$ & $56 \pm 6$ \\
\hline RB (C-K-01) & K-f & $110 \pm 4$ & $55 \pm 4$ \\
\hline
\end{tabular}

To simulate somewhat more reservoir-like conditions, COBR-treated mica samples, identical to those described above, were used. In cases where reservoir brine compositions were available, brine and oil from the same reservoir were matched. The results of the COBR treatments and exposure to mud fractions are summarized in Table 10 and shown in Fig. 6 for the WW oils and Figs. 7 and 8 for the OW group of oils for 
comparison with advancing angles after similarly treated samples were aged for one week or more in either the K-f or L-c mud fractions.

Table 10. Effect of mud samples on mica aged in brines and oils

\begin{tabular}{|c|c|c|c|c|c|c|}
\hline \multicolumn{2}{|c|}{ Aging combination } & \multicolumn{2}{c|}{$\mathbf{7}$ days in SBM } & \multicolumn{2}{c|}{$27 / 36$ days in SBM } \\
\hline Brine (day) & Oil (21 days) & SBM fraction & $\boldsymbol{\theta}_{\mathbf{A}}$ & $\boldsymbol{\theta}_{\mathbf{R}}$ & $\boldsymbol{\theta}_{\mathbf{A}}$ & $\boldsymbol{\theta}_{\mathbf{R}}$ \\
\hline RB & C-B2-01 & K-f & $65 \pm 6$ & $20 \pm 3$ & $67 \pm 4$ & $21 \pm 3$ \\
\hline RB & C-K-01 & L-c & $60 \pm 5$ & $28 \pm 4$ & $60 \pm 2$ & $27 \pm 1$ \\
\hline RB & C-L-01 & L-c & $66 \pm 4$ & $27 \pm 3$ & $64 \pm 3$ & $25 \pm 2$ \\
\hline pH 4 & E-1XC0-01 & K-f & $120 \pm 8$ & $28 \pm 5$ & $129 \pm 13$ & $29 \pm 3$ \\
\hline pH 4 & C-A2-00 & K-f & $58 \pm 3$ & $22 \pm 2$ & $58 \pm 4$ & $22 \pm 3$ \\
\hline pH 4 & S-ven-41 & K-f & $75 \pm 6$ & $23 \pm 2$ & $76 \pm 6$ & $22 \pm 3$ \\
\hline pH 4 & E-1XC0-01 & L-c & $64 \pm 7$ & $45 \pm 7$ & $73 \pm 2$ & $40 \pm 3$ \\
\hline pH 4 & C-A2-00 & L-c & $56 \pm 4$ & $23 \pm 2$ & $58 \pm 3$ & $22 \pm 2$ \\
\hline pH 4 & S-Ven-41 & L-c & $55 \pm 5$ & $24 \pm 5$ & $59 \pm 4$ & $26 \pm 2$ \\
\hline SSW & E-1XC0-01 & K-f & $47 \pm 4$ & $21 \pm 3$ & & \\
\hline SSW & C-A2-00 & K-f & $110 \pm 9$ & $29 \pm 1$ & & \\
\hline SSW & S-Ven-41 & K-f & $68 \pm 13$ & $11 \pm 1$ & & \\
\hline SSW & E-1XC0-01 & L-c & $47 \pm 2$ & $33 \pm 5$ & $48 \pm 2$ & $31 \pm 6$ \\
\hline SSW & C-A2-00 & L-c & $64 \pm 6$ & $35 \pm 5$ & $58 \pm 3$ & $22 \pm 2$ \\
\hline SSW & S-Ven-41 & L-c & $45 \pm 3$ & $34 \pm 4$ & & \\
\hline
\end{tabular}

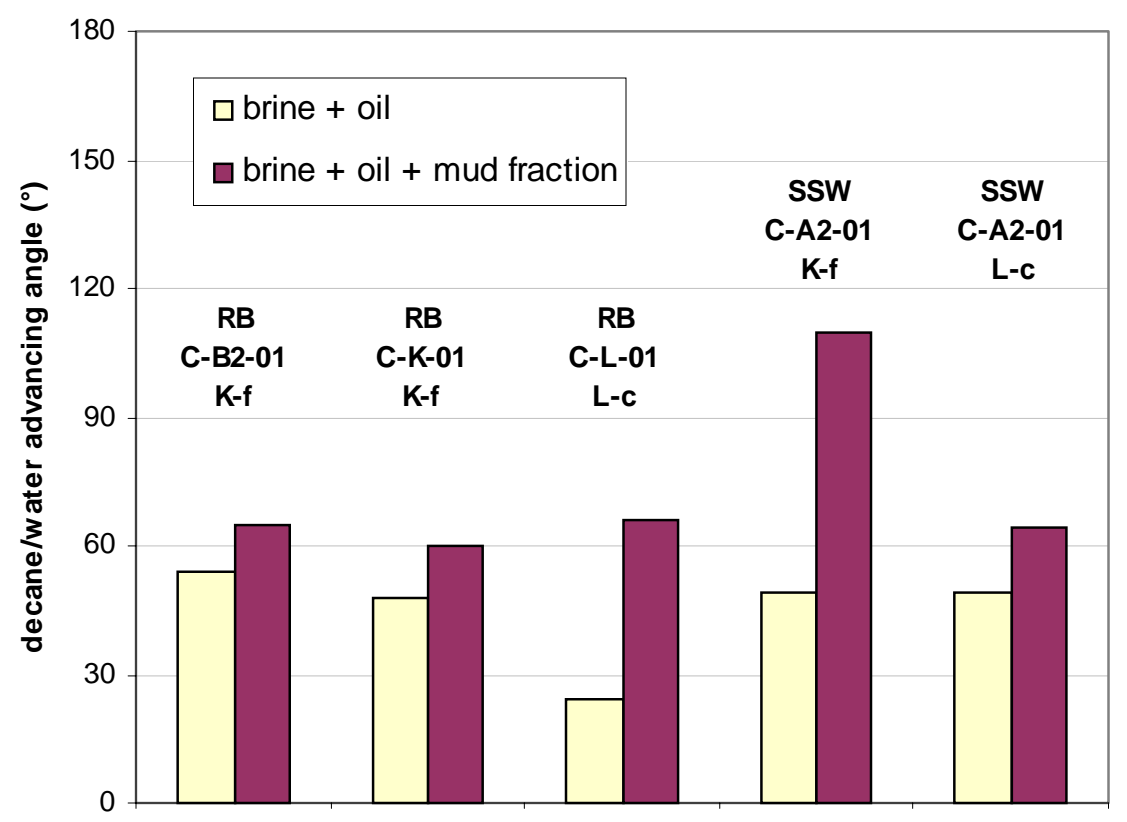

brine/oil/mud fraction

Figure 6. Effect of mud fractions on COBR-treated mica surfaces--WW oils and reservoir brines or synthetic sea water. 


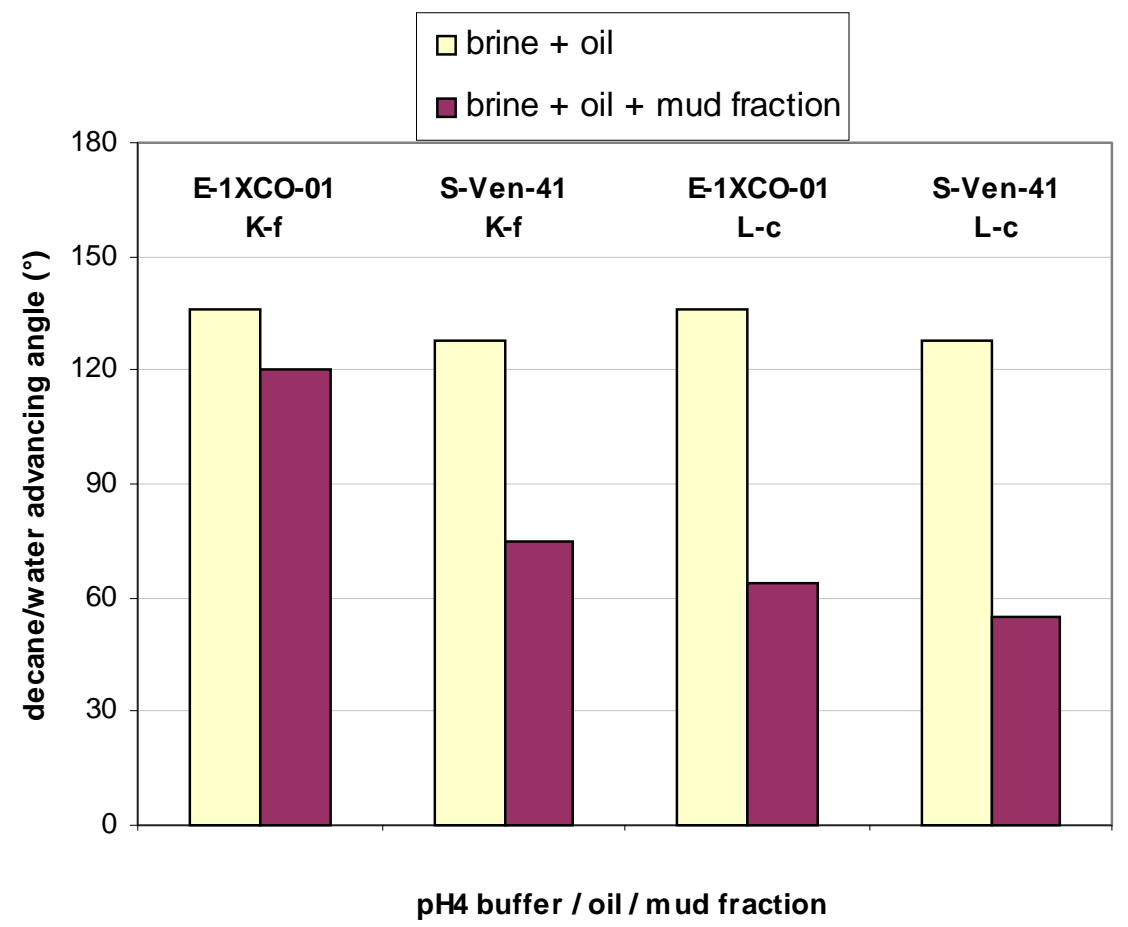

Figure 7. Effect of mud fractions on COBR-treated mica surfaces- $\mathrm{OW}$ oils and $\mathrm{pH} 4$ buffer.

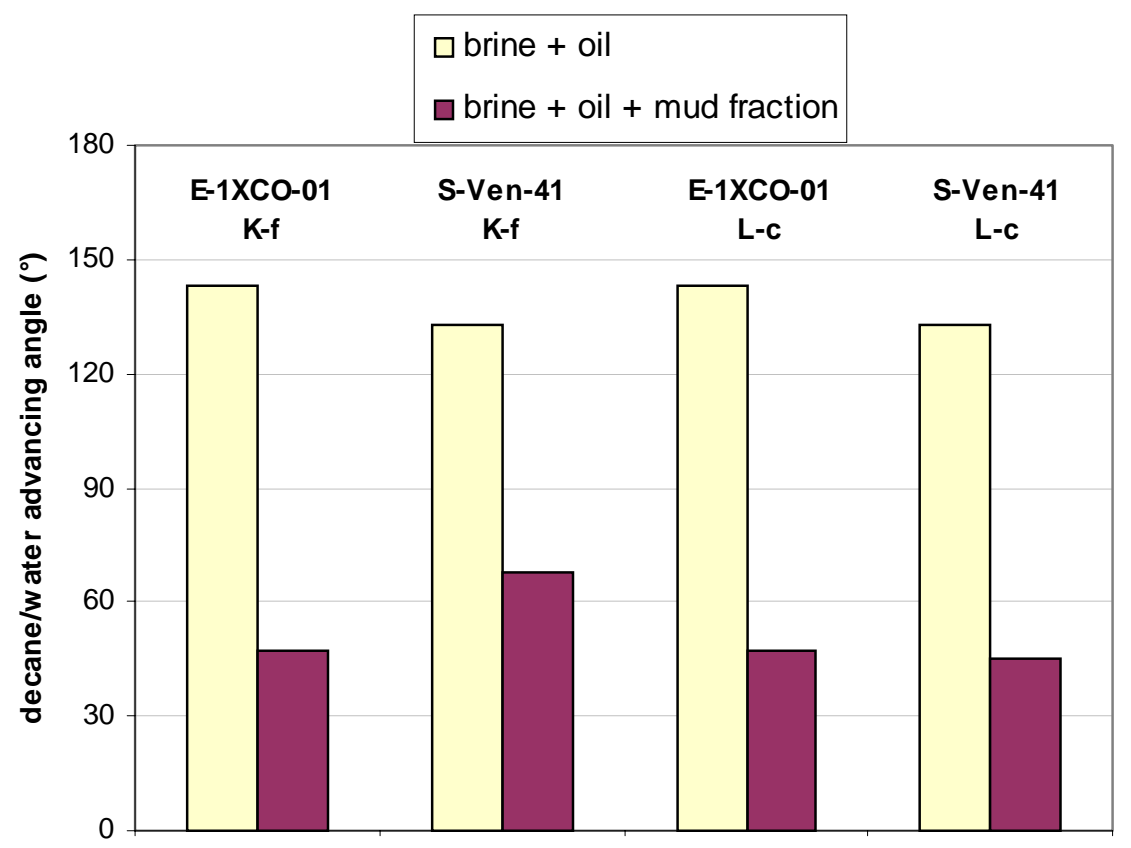

SSW / oil / mud fraction

Figure 8. Effect of mud fractions on COBR-treated mica surfaces-OW oils and SSW. 
Aging for more than 7 days in the mud samples made little difference in the results, as shown in Fig. 9.

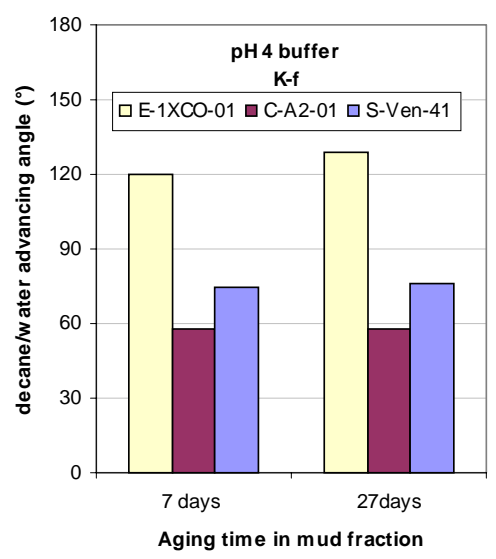

(a) $\mathrm{pH} 4, \mathrm{~K}-\mathrm{f}$

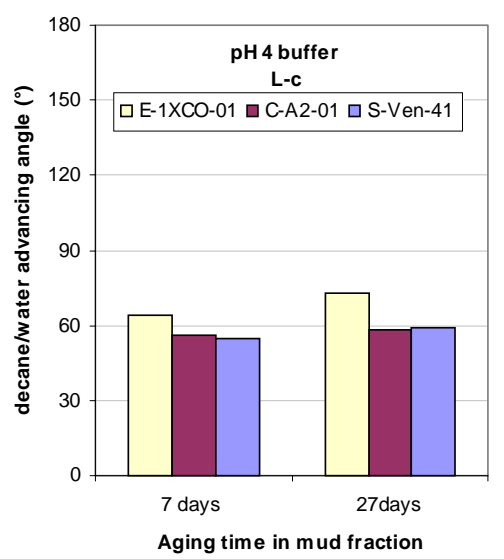

(b) $\mathrm{pH} 4$, L-c

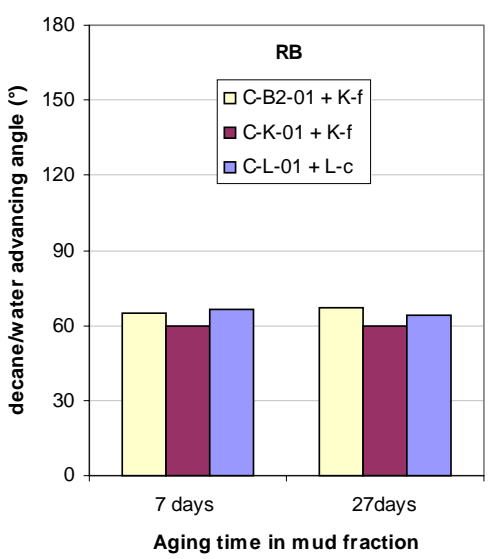

(c) RB

Figure 9. Extending the aging time in either mud fraction beyond one week has little further effect on the change in the water-advancing contact angle for a variety of combinations of oil and mud fraction, with or without brine.

In Fig. 10a, effects of K-f and L-c are compared for COBR-treated surfaces produced by three different crude oils with $\mathrm{pH} 4$ buffer. Figure 10b compares the same oil/mud fraction combinations for surfaces initially exposed to SSW. Results in both cases are similar. 


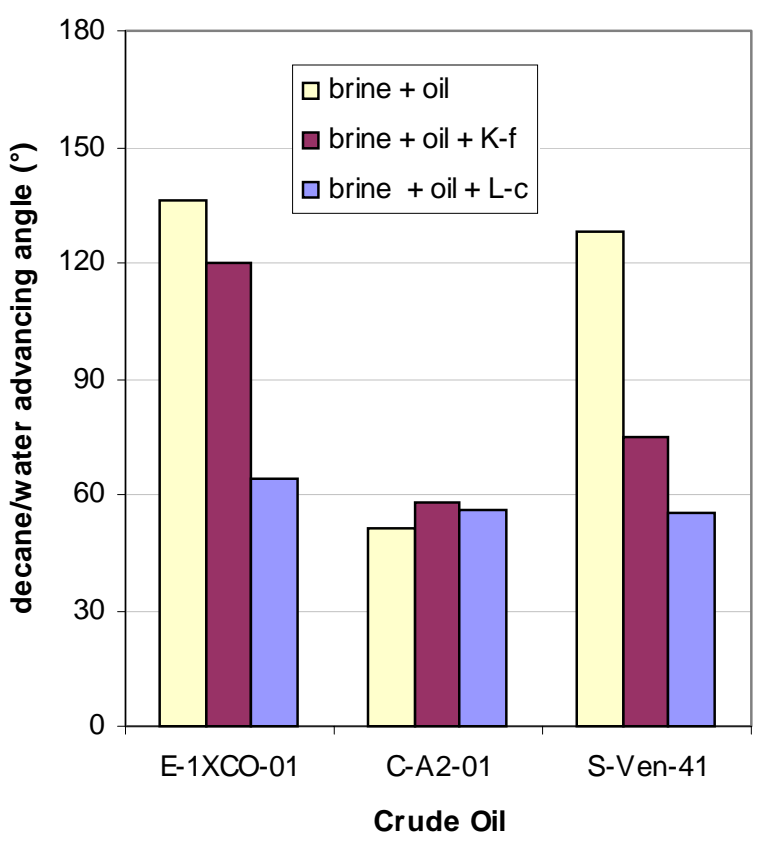

(a) samples pretreated with $\mathrm{pH} 4$ buffer

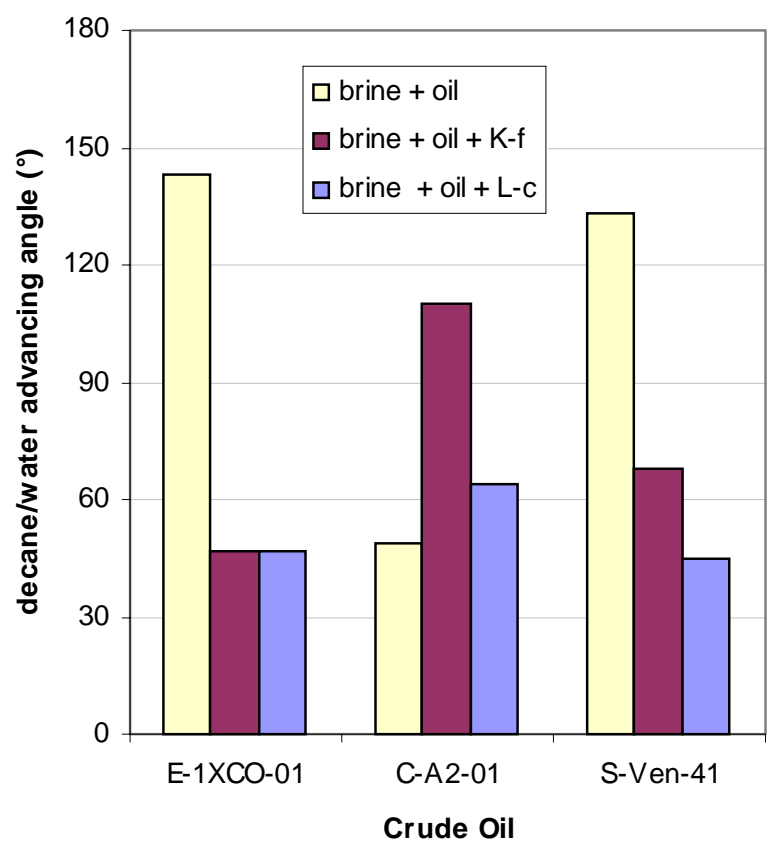

(b) samples pretreated with SSW

Figure 10. Comparison of the effects of K-f filtrate and L-c centrifugate on COBR-treated mica samples.

The effect of the brine used to pre-treat mica during the COBR treatment sequence varies with crude oil composition. For S-Ven-41, there appears to be little effect of brine composition on the subsequent effect of exposure to either of the mud fractions. The changes in samples after exposure to the mud samples were similar, regardless of the composition of the original brine. For crude oil E-1XCO-01, the reduction in contact angles was greater for the surface treated first with SSW, whereas for C-A2-00, the opposite trend was observed.

It is possible that these differences are related to the primary mechanisms of wetting alteration (Buckley et al., 1998), although an interpretation based on the limited amount of data available must be regarded as speculative. S-Ven-41 is the most asphaltic of these three oils and the one with the least stable asphaltenes. If interactions are dominated by surface precipitation, brine composition would only be important if one of the brines produced stable wetting films. In the case of E-1XCO-01, acid/base mechanisms may dominate, since contact angles are reduced most dramatically for the SSW case and less change occurs with the pH4 brine. Finally, since the SSW case is less affected (contact angles are actually higher after mud treatments) perhaps C-A2-00 interacts with the surface through ion-binding mechanisms. 


\section{Cleaning}

Since core is often exposed to drilling fluid components, it is essential that cleaning methods be established that remove contaminants so that the cleaned surface can interact with brine and crude oil to accurately reproduce the original wetting condition. Results of washing with single organic solvents and with sequences of solvents are given in Tables $11-13$. The shaded cells indicate results for samples that were rinsed with toluene and submerged in decane, but were not washed with any additional solvents. Table 11 contains results for reservoir brine COBR-treated surfaces, $\mathrm{pH} 4$ buffer COBR samples are in Table 12, and SSW COBR samples are in Table 13. Results are mixed.

\section{Restoration of wettability}

Probably the most important question is whether the original wettability established by COBR interactions can be reestablished in a cleaned core. The results of surface tests shown in Fig. 11 and summarized in Table 14 are encouraging. Water advancing angles are compared for surfaces treated by the standard COBR sequence (the initial brine and oil indicated for each set of results) with similarly treated surfaces that were subsequently exposed to one of the drilling fluid fractions, washed, and restored by a second exposures to crude oil. In all cases, preferentially water-wet surfaces were returned to water wet conditions and preferentially oil-wet surfaces to oil-wet conditions. The contact angles after treatment were often somewhat lower than on the original COBR-treated surfaces, but there are exceptions that make it difficult to generalize about the effects of either the K-f or L-c fluids.

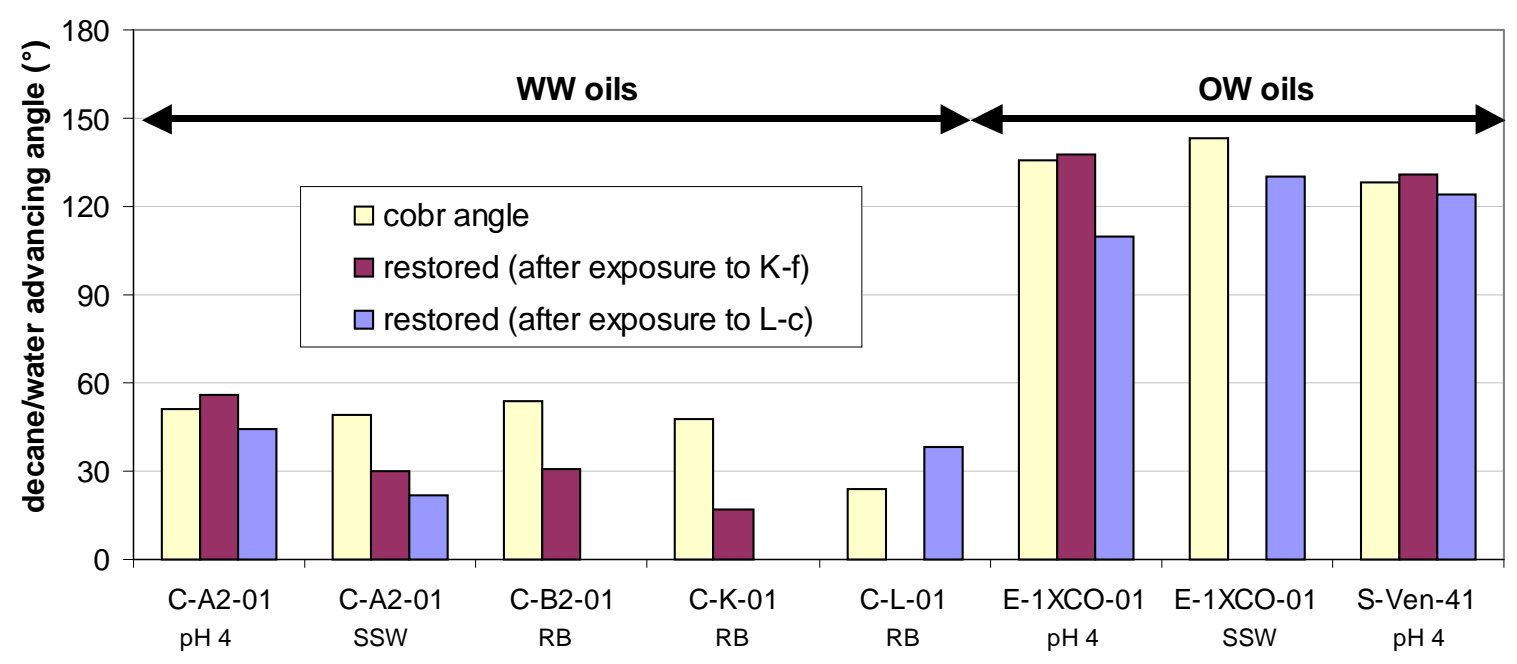

Figure 11. Restoration of wettability by COBR interactions. Water-advancing angles are compared for mica surfaces treated by the standard COBR sequence to those obtained after exposure to drilling fluid fractions, washing, and repeated COBR exposures. 
Table 11. Advancing angles (decane/water) for washing tests on COBR mica samples aged in synthetic reservoir brine, oil and mud samples, then washed as indicated.

\begin{tabular}{|c|c|c|c|}
\hline \multirow[b]{2}{*}{ Oil, mud sample combinations: } & \multicolumn{3}{|c|}{ water advancing contact angle, $\theta_{\mathrm{A}}\left({ }^{\circ}\right)$} \\
\hline & \multirow{2}{*}{$\begin{array}{c}\text { C-B2-01 } \\
\text { K-f filtrate }\end{array}$} & \multirow{2}{*}{$\begin{array}{c}\text { C-K-01 } \\
\text { K-f filtrate }\end{array}$} & \multirow{2}{*}{$\begin{array}{c}\text { C-L-01 } \\
\text { L-c centrifugate }\end{array}$} \\
\hline Washing solvent(s) & & & \\
\hline Toluene $(\mathrm{T})$ rinse only & $65 \pm 6$ & $60 \pm 5$ & $66 \pm 5$ \\
\hline Methylene chloride $\left(\mathrm{CH}_{2} \mathrm{Cl}_{2}\right)$ & $50 \pm 7$ & $48 \pm 4$ & $52 \pm 3$ \\
\hline hot $\mathrm{CH}_{2} \mathrm{Cl}_{2}\left(37^{\circ} \mathrm{C}\right)$ & $63 \pm 5$ & & \\
\hline methanol $\left(\mathrm{CH}_{3} \mathrm{OH}\right)$ & $42 \pm 4$ & $30 \pm 2$ & $41 \pm 2$ \\
\hline chloroform $\left(\mathrm{CHCl}_{3}\right), \mathrm{CH}_{2} \mathrm{Cl}_{2}$ & $36 \pm 2$ & & \\
\hline $\mathrm{CHCl}_{3}, \mathrm{CH}_{3} \mathrm{OH}$ & $36 \pm 1$ & $39 \pm 3$ & $39 \pm 3$ \\
\hline $\mathrm{CH}_{2} \mathrm{Cl}_{2}, \mathrm{CH}_{3} \mathrm{OH}$ & & $50 \pm 9$ & $39 \pm 3$ \\
\hline $\mathrm{CH}_{3} \mathrm{OH}, \mathrm{CH}_{2} \mathrm{Cl}_{2}$ & $44 \pm 2$ & $50 \pm 3$ & \\
\hline $\mathrm{CH}_{2} \mathrm{Cl}_{2}, \mathrm{CHCl}_{3}, \mathrm{CH}_{3} \mathrm{OH}$ & & $37 \pm 2$ & $35 \pm 3$ \\
\hline hot $\mathrm{CH}_{2} \mathrm{Cl}_{2}, \mathrm{CHCl}_{3}, \mathrm{CH}_{3} \mathrm{OH}$ & $63 \pm 3$ & $57 \pm 5$ & $57 \pm 3$ \\
\hline Acetic acid (1/10 of glacial) & & $71+3$ & \\
\hline
\end{tabular}

Table 12. Advancing angles (decane/water) for washing tests on COBR mica samples aged in pH 4 buffer, oil and mud samples, then washed as indicated.

\begin{tabular}{|c|c|c|c|c|}
\hline \multirow{2}{*}{ Oil } & \multirow{2}{*}{$\begin{array}{c}\text { Mud } \\
\text { fraction }\end{array}$} & \multirow{2}{*}{ Toluene rinse only } & \multicolumn{2}{|c|}{ Washed with } \\
\hline & & & $\mathrm{T}+\mathrm{CH}_{3} \mathrm{OH}$ & $\mathrm{T}+\mathrm{C}_{2} \mathrm{H}_{4}\left(\mathrm{NH}_{2}\right)_{2}$ \\
\hline & & $\boldsymbol{\theta}_{\mathrm{A}}$ & $\theta_{\mathrm{A}}$ & $\theta_{\mathrm{A}}$ \\
\hline C-A2-00 & K-f & $58 \pm 3$ & & $12 \pm 1$ \\
\hline E-1XC0-01 & K-f & $120 \pm 8$ & & $39 \pm 6$ \\
\hline S-Ven-41 & K-f & $75 \pm 6$ & & $20 \pm 3$ \\
\hline C-A2-00 & L-c & $56 \pm 4$ & $70 \pm 2$ & $18 \pm 3$ \\
\hline E-1XC0-01 & L-c & $64 \pm 7$ & $102 \pm 4$ & $25 \pm 2$ \\
\hline S-Ven-41 & L-c & $55 \pm 5$ & $104 \pm 1$ & $24 \pm 1$ \\
\hline
\end{tabular}

Table 13. Advancing angles (decane/water) for washing tests on COBR mica samples aged in SSW buffer, oil and mud samples, then washed as indicated.

\begin{tabular}{|l|c|c|c|c|c|}
\hline \multirow{2}{*}{ Oil } & \multirow{2}{*}{$\begin{array}{c}\text { Mud } \\
\text { fraction }\end{array}$} & \multirow{2}{*}{$\begin{array}{c}\text { Toluene rinse } \\
\text { only }\end{array}$} & $\mathbf{T}+\mathbf{C H}_{\mathbf{3}} \mathbf{O H}$ & $\mathbf{T}+\mathbf{C}_{\mathbf{2}} \mathbf{H}_{\mathbf{4}}\left(\mathbf{N H}_{\mathbf{2}} \mathbf{2}_{\mathbf{2}}\right.$ & $\mathbf{T}+\mathbf{C H}_{\mathbf{2}} \mathbf{C l}_{\mathbf{2}}$ \\
\hline & & $\boldsymbol{\theta}_{\mathbf{A}}$ & $\boldsymbol{\theta}_{\mathbf{A}}$ & $\boldsymbol{\theta}_{\mathbf{A}}$ & $\boldsymbol{\theta}_{\mathbf{A}}$ \\
\hline C-A2-00 & K-f & $110 \pm 9$ & & $33 \pm 5$ & \\
\hline E-1XC0-01 & K-f & $47 \pm 4$ & $70 \pm 9$ & $57 \pm 10$ & \\
\hline S-Ven-41 & K-f & $68 \pm 13$ & $93 \pm 10$ & $49 \pm 3$ & \\
\hline C-A2-00 & L-c & $64 \pm 6$ & $73 \pm 2$ & $32 \pm 2$ & $24 \pm 2$ \\
\hline E-1XC0-01 & L-c & $47 \pm 2$ & $66 \pm 3$ & $25 \pm 2$ & \\
\hline S-Ven-41 & L-c & $45 \pm 3$ & $56 \pm 2$ & $46 \pm 3$ & \\
\hline
\end{tabular}


Table 14. Summary of the decane/water contact angles (advancing) for mica aged in brine, oil, mud sample, then washed and restored.

\begin{tabular}{|c|c|c|c|c|c|c|}
\hline $\begin{array}{l}\text { Step 1 } \\
\text { Age for } 1 \\
\text { day in } \\
\text { brine }\end{array}$ & $\begin{array}{l}\frac{\text { Step 2 }}{\text { Aged for 21 }} \\
\text { days in Oil }\end{array}$ & $\begin{array}{l}\theta_{\mathrm{A}} \text { after } \\
\text { Step } 2\end{array}$ & $\begin{array}{c}\text { Step 3 } \\
\text { Age for } 7 \\
\text { days in mud } \\
\text { fraction }\end{array}$ & $\begin{array}{l}\theta_{\mathrm{A}} \text { after } \\
\text { Step } 3\end{array}$ & $\begin{array}{l}\text { Step 4 } \\
\text { Wash and re } \\
\text { age for } 21 \text { days } \\
\text { in oil }\end{array}$ & $\begin{array}{l}\theta_{\mathrm{A}} \text { after } \\
\text { Step } 4\end{array}$ \\
\hline $\mathrm{pH} 4$ & E-1XC0-01 & $136 \pm 5$ & K-f & $120 \pm 8$ & E-1XC0-01 & $138 \pm 3$ \\
\hline $\mathrm{pH} 4$ & C-A2-00 & $51 \pm 4$ & K-f & $58 \pm 3$ & C-A2-00 & $56 \pm 3$ \\
\hline $\mathrm{pH} 4$ & S-Ven-41 & $128 \pm 5$ & K-f & $75 \pm 6$ & S-Ven-41 & $131 \pm 3$ \\
\hline $\mathrm{pH} 4$ & E-1XC0-01 & $136 \pm 5$ & L-c & $64 \pm 7$ & E-1XC0-01 & $110 \pm 4$ \\
\hline $\mathrm{pH} 4$ & C-A2-00 & $51 \pm 4$ & L-c & $56 \pm 4$ & C-A2-00 & $44 \pm 3$ \\
\hline $\mathrm{pH} 4$ & S-Ven-41 & $128 \pm 5$ & L-c & $55 \pm 5$ & S-Ven-41 & $124 \pm 4$ \\
\hline SSW & E-1XC0-01 & $143 \pm 6$ & K-f & $47 \pm 4$ & E-1XC0-01 & $*$ \\
\hline SSW & C-A2-00 & $49 \pm 3$ & K-f & $110 \pm 9$ & C-A2-00 & $30 \pm 3$ \\
\hline SSW & S-Ven-41 & $133 \pm 5$ & K-f & $68 \pm 13$ & S-Ven-41 & $*$ \\
\hline SSW & E-1XC0-01 & $143 \pm 6$ & L-c & $47 \pm 4$ & E-1XC0-01 & $130 \pm 5$ \\
\hline SSW & C-A2-00 & $49 \pm 3$ & L-c & $64 \pm 6$ & C-A2-00 & $22 \pm 2$ \\
\hline SSW & S-Ven-41 & $133 \pm 5$ & L-c & $45 \pm 3$ & S-Ven-41 & $*$ \\
\hline $\mathrm{RB}$ & C-L-01 & $24 \pm 3$ & L-c & $66 \pm 4$ & C-L-01 & $38 \pm 3$ \\
\hline $\mathrm{RB}$ & C-K-01 & $48 \pm 3$ & K-f & $60 \pm 5$ & C-K-01 & $17 \pm 4$ \\
\hline $\mathrm{RB}$ & C-B2-01 & $54 \pm 5$ & K-f & $65 \pm 6$ & C-B-01 & $31 \pm 3$ \\
\hline
\end{tabular}

* None of the "cleaned" samples were sufficiently water-wet to use in restoration tests.

\section{Plans for Future Research}

The next step in the surface studies portion of this project is to replicate experiments such as those reported here with known compounds and with mixtures of drilling fluid additives. Testing of a variety of products is underway.

Under the core-testing task of this project, the first step is to develop a standard sequence of treatment and imbibition measurement steps. A report on the initial phase of the core work is in preparation.

\section{Acknowledgements}

Most of the fluids used in this study were provided by ChevronTexaco. Additional oils were provided by TotalFinaElf and by Shell. 


\section{References}

Al-Maamari, R.S.H. and Buckley, J.S.: "Asphaltene Precipitation and Alteration of Wetting: Can Wettability Change During Oil Production?" paper SPE 59292 at the 2000 SPE/DOE IOR Symposium, Tulsa, 3-5 Apr.

Buckley, J.S.: "Effective Wettability of Minerals Exposed to Crude Oil," Current Opinion in Colloid \& Interface Sci. (2001) 6, 191-196.

Buckley, J.S., Liu, Y., and Monsterleet, S.: "Mechanisms of Wetting Alteration by Crude Oils," SPEJ (Mar. 1998) 3, 54-61.

Buckley, J.S., Takamura, K., and Morrow, N.R.: "Influence of Electrical Surface Charges on the Wetting Properties of Crude Oils," SPE RE (1989) 4 (3), 332-340.

Liu, Y. and Buckley, J.S.: "Evolution of Wetting Alteration by Adsorption from Crude Oil," SPEFE (Mar. 1997) 12, 5-11.

Liu, L. and Buckley, J.S.: "Alteration of Wetting of Mica Surfaces," J. Pet. Sci. Eng. (1999) 24, 75-83.

McCaffery, F., Buckley, J.S., Silveira, R., Lekkala, R.K., Goggin, D., and McCarty, A.: "Wettability and Water-Oil Displacement Investigations for Some High Permeability Turbidite Reservoirs," paper 2002-32 presented at the International Symposium of the Society of Core Analysts, 23-25 Sept. 